\title{
REGEPE

\section{DISCURSO E EMPREENDEDORISMO SOCIAL: O QUE A PRÁTICA DE ESTUDANTES ENGAJADOS EM PROJETOS SOCIAIS PODE REVELAR?}

\author{
1 Andrea Aparecida da Costa Mineiro \\ 2 Fernanda Junia Dornela \\ 3 Isabel Cristina da Silva Arantes \\ 4 Juliano Silva Cougo
}

\section{Resumo}

Objetivo do estudo: Este estudo objetiva compreender, sob a ótica da Análise Crítica do Discurso (ACD), as concepções discursivas dos estudantes sobre a experiência prática de projetos sociais na disciplina de Empreendedorismo Social (ES) do curso de Administração da UNIFEI-MG.

Metodologia/abordagem: Assim como sugere Norman Fairclough $(2001 ; 2003)$, considerouse o discurso como uma prática social e, foram analisadas as práticas textuais, discursivas e sociais dos estudantes investigados. Os discursos foram coletados por meio da realização de dois grupos focais e os resultados analisados com base na ACD.

Principais resultados: Os resultados apontam que há divergências nas produções discursivas de ambos os grupos de estudantes, sendo que o grupo com alto aproveitamento acadêmico revela um discurso pautado na racionalidade substantiva, com emoção, intensidade e se baseia em valores direcionados a um bem coletivo. Em contraste, o grupo que obteve baixo aproveitamento acadêmico se pauta na racionalidade instrumental, e na necessidade de se trabalhar por um retorno financeiro.

Contribuições teóricas/metodológicas: Evidenciou-se que as concepções discursivas externalizadas refletem a prática discursiva do ES, mas ao mesmo tempo demarcam o discurso gerencial hegemônico da Administração e sua lógica instrumental.

Relevância/originalidade: Kedmenec et al. (2016) e Shahverdi et al. (2018) reforçam a relevância da incorporação do conteúdo discursivo de ES nos cursos tradicionais. Constatase que o ES é capaz de proporcionar soluções efetivas para diversos problemas sociais, econômicos e ambientais, na perspectiva de valorização do caráter humanitário e da emancipação social (Shahverdi et al., 2018).

Palavras-chave: Empreendedorismo Social. Análise Crítica do Discurso (ACD). Curso de Administração.

Recebido: 14/03/2019 / Aprovado: 12/12/2019

Editor responsável: Profa. Dra. Vânia Maria Nassif

Processo de avaliação: Double Blind Review

Doi: https://doi.org/10.14211/regepe.v9i3.1327

\footnotetext{
${ }^{1}$ Universidade Federal de Itajuba - UNIFEI, Minas Gerais, (Brasil). E-mail: andreamineiro@uol.com.br Orcid id: http://orcid.org/0000-0003-1155-7333

${ }^{2}$ Universidade Federal de Lavras - UFLA, Minas Gerais, (Brasil).E-mail: fernandadornela.ufv@gmail.com Orcid id: https://orcid.org/0000-0001-7442-2140

${ }^{3}$ Universidade Federal de Itajuba - UNIFEI, Minas Gerais, (Brasil). E-mail: isabel.adm@unifei.edu.br Orcid id: https://orcid.org/0000-0002-6498-5254

${ }^{4}$ Universidade Federal de Lavras- UFLA, Minas Gerais, (Brasil). E-mail: julianocougo00@gmail.com Orcid id: http://orcid.org/0000-0002-8781-2479
}

Rev. de Empreendedorismo e Gest. Pequenas Empres. | São Paulo, v.9 | n.3 | p. 303-330 | Maio/Ago. 2020. 


\title{
DISCOURSE AND SOCIAL ENTREPRENEURSHIP:WHAT CAN THE PRATICE OF STUDENTS ENGAGED IN SOCIAL PROJECTS REVEAL?
}

\begin{abstract}
Purpose: This study aims to understand, from the perspective of Critical Analysis of Discourse (CAD), the students' discursive conceptions on the practical experience of social projects in the Social Entrepreneurship (SE) class of the Business Administration course at UNIFEI-MG.
\end{abstract}

Design/methodology: As Norman Fairclough (2001; 2003) suggests, discourse was considered a social practice and the textual, discursive and social practices of the investigated students were analyzed. The discourses were collected through two focus groups and the results analyzed based on the CAD.

Main findings: The results show that there are divergences in the discursive productions of both groups of students, as the high academic performance group reveals a discourse based on a substantive rationality, with emotion, intensity and based on values directed to a collective well-being. In contrast, the low academic performance group is guided by an instrumental rationality, and by the need to work for a financial return.

Theoretic/methodology contributions: It became evident that the externalized discursive conceptions reflect the discursive practice of the SE, but at the same time they denote the hegemonic management discourse of Administration and its instrumental logic.

Originality/value: Kedmenec et al. (2016) and Shahverdi et al. (2018) reinforce the relevance of incorporating the discourse content of SE in traditional courses. It is verified that SE is capable of providing effective solutions to several social, economic and environmental problems, from the perspective of valuing the human capital and developing social emancipation (Shahverdi et al., 2018).

Keywords: Social Entrepreneurship. Critical Analysis of Discourse (DAC). Business Administration Course. 


\section{DISCURSO Y EMPRENDIMIENTO SOCIAL: ¿QUÉ PRÁTICA DE LOS ESTUDIANTES COMPROMETIDOS EN PROYECTOS SOCIALES PUEDE REVELAR?}

\section{Resumen}

Objetivo del estudio: El objetivo de este estudio es comprender las concepciones discursivas de los estudiantes sobre la experiencia práctica de proyectos sociales en la disciplina del espíritu empresarial social del curso de Administración de UNIFEI - MG, desde la perspectiva del Análisis Crítico del Discurso (ACD).

Metodología/enfoque: Como lo sugiere Norman Fairclough (2001, 2003), el discurso fue considerado como una práctica social y, por lo tanto, fueron analizadas las prácticas textuales, discursivas y sociales de los estudiantes investigados. Los discursos se recopilaron a través de dos grupos focales y los resultados analizados se basan en el Análisis Crítico del Discurso.

Resultados principales: Los resultados muestran que existen divergencias entre los discursos de ambos grupos de estudiantes, y el grupo con alto rendimiento revela un discurso basado en la racionalidad sustantiva, con emoción, intensidad y basado en valores dirigidos hacia un bien colectivo, y el grupo que obtuvo una baja utilización se basa en la racionalidad instrumental y la necesidad de trabajar para obtener un rendimiento financiero.

Contribuciones teóricas/metodológicas: Además, se evidenció que las concepciones discursivas externalizadas reflejan la práctica discursiva del emprendimiento social, pero al mismo tiempo delimitan el discurso gerencial hegemónico de la Administración y su lógica instrumental.

Relevancia/originalidad: Kedmenec y col. (2016) y Shahverdi et al. (2018) refuerzan la relevancia de incorporar el contenido discursivo del emprendimiento social (ES) en los cursos tradicionales. Se encuentra que la educación superior es capaz de proporcionar soluciones efectivas a diversos problemas sociales, económicos y ambientales, desde la perspectiva de valorar el carácter humanitario y la emancipación social (Shahverdi et al., 2018).

Palabras clave: Emprendimiento Social. Análisis Crítico del Discurso (ACD). Curso de administración. 


\section{INTRODUÇÃO}

A Análise Crítica do Discurso (ACD) é uma abordagem teórico-metodológica que considera a linguagem uma prática social, em razão de ela ser capaz de construir identidades, valores, relações e perspectivas acerca da realidade. Utilizar a ACD em estudos significa reconhecer que o discurso cria, condiciona e reforça estruturas de poder e de dominação, configurando ideologias e hegemonias sociais. Isso porque, por meio de interligações sociais e de constituições de ordens discursivas, grande parte dos discursos elabora e fortalece matrizes socialmente preponderantes, sustentadas pela luta hegemônica em organizações (Fairclough, 2001). Desse modo, a ACD é importante para pesquisas sociais com propostas críticas de análises, haja vista a centralidade que a linguagem ocupa no capitalismo atual (Resende \& Ramalho, 2004).

As universidades, financiadas pelo capital público ou privado, não fogem à regra das cadeias hegemônicas, porque se rendem à função da lógica produtiva, reproduzindo tanto o ideário do mercado (Chauí, 2001; Faria \& Meneghetti, 2010) quanto os discursos ideológicos do campo. Então, se, por um lado, a universidade propaga a logicidade mercantil, produzindo "mão de obra superior"; por outro, ela perde a finalidade social e ética de sua produção (Tragtenberg, 2004).

A propósito, no meio acadêmico, o ensino da Administração está mais voltado às premissas e aos discursos de eficiência e de maximização de lucros, do que à prática de valores sociais e humanos. Isso acontece porque, em geral, os cursos têm a finalidade de formar administradores para atuar, de maneira ferramental e pouco crítica no mercado, ao invés de desenvolver agentes conscientes de seu papel político (Ribeiro \& Sacramento, 2009). Isso é comprovado pelas poucas disciplinas oferecidas nos cursos de Administração sobre temáticas sociais, por não serem consideradas prioritárias, embora fundamentais à formação do administrador (Aktouf, 2004; Oliveira, Sant'anna, \& Diniz, 2014; Shahverdi et al., 2018). Essa situação, no entanto, vem gradativamente se modificando, em função das mudanças nas práticas de mercado, cuja tendência é direcionar os cursos de Administração para a formação de atores comprometidos com as causas sociais, capazes de atuar em contextos socioeconômicos menos favorecidos (Oliveira et al., 2014; Kedmenec et al., 2016). Nesse sentido, as organizações de diversos setores estão investindo em projetos e vislumbrando a gestão social e/ou sustentável de seus ramos de atividades. 
Um ensino adequado pode gerar novos negócios, que, por extensão, proporcionarão o desenvolvimento socioeconômico (Weise et al., 2014). Isso explica a preocupação com a formação e a atuação socioprofissional do administrador, tanto por parte das Instituições de Ensino Superior (IES) como de pesquisadores e estudiosos, pois se sabe o quão desafiador é formar profissionais reflexivos, críticos e preparados para lidar com toda a complexidade da vida social (Aktouf, 2004).

Para tanto, é relevante a incorporação do conteúdo discursivo do Empreendedorismo Social (ES) nos cursos tradicionais, a fim de que sejam desenvolvidas soluções efetivas para diversos problemas sociais, econômicos e ambientais, por meio da atuação de organizações e de agentes preocupados com as mazelas da sociedade, que valorizam o caráter humanitário e a emancipação social (Kedmenec et al., 2016; Shahverdi et al., 2018). Nesse sentido, os cursos difusores da concepção do ES podem promover, por conseguinte, a conscientização sobre os problemas sociais, além de desenvolver nos estudantes a competência e a confiança para a tomada de iniciativas geradoras de uma nova mundividência (Kedmenec et al., 2016).

Conforme essa perspectiva, e partindo do pressuposto de que o engajamento com a prática do ES tende a gerar uma mudança no discurso gerencial hegemônico dos estudantes de Administração, este estudo, sob a orientação teórico-metodológica da ACD, analisou resultados práticos e discursivos da enunciação discente na disciplina de Empreendedorismo Social. Considerando a relação íntima e dialética entre os discursos e as práticas sociais, buscou-se, então, responder ao seguinte questionamento: quais são as concepções discursivas dos estudantes sobre a experiência prática de projetos sociais na disciplina de Empreendedorismo Social, do curso de Administração da Unifei (MG)?

O objetivo central da investigação foi compreender, sob a ótica da ACD, as concepções discursivas dos estudantes sobre a experiência prática de projetos sociais na disciplina de ES do curso de Administração da Unifei (MG). Especificamente, buscou-se: (i) desvelar os discursos predominantes sobre a experiência vivida; (ii) averiguar se o discurso gerencial hegemônico da Administração está presente nas práticas discursivas dos estudantes; e (iii) elucidar as amostras discursivas sobre as dificuldades enfrentadas no campo. Para operacionalizar essa investigação, dois grupos focais foram formados, com estudantes que cursaram a disciplina no período 
de 2013 a 2017, a fim de extrair das enunciações práticas discursivas e sociais e demais elementos do discurso.

Em termos estruturais, o estudo está subdividido em cinco partes: (1) as informações apresentadas nesta introdução; (2) a orientação teórico-metodológica da ACD e do ES; (3) os procedimentos metodológicos seguidos na prática da pesquisa; (4) os resultados e as análises discursivas; e (5) a contextualização das considerações finais, seguidas das referências bibliográficas que embasaram o estudo.

\section{ESCOPO TEÓRICO-METODOLÓGICO}

Este item se destina à discussão conceitual sobre a Análise Crítica do Discurso (ACD) e o Empreendedorismo Social (ES), apresentando brevemente os construtos teóricos que nortearam a pesquisa aqui apresentada.

\subsection{Compreendendo as orientações da ACD}

A perspectiva da ACD nasce na Europa, por volta da década de 1980, oriunda dos estudos do linguista Norman Fairclough que, tendo reconhecido a linguagem como parte irredutível da vida social, concentrou esforços em desvelar as relações existentes entre os fatos sociais (práticas sociais) e a linguagem (práticas discursivas). Conforme Fairclough (2001), a ACD é uma perspectiva teórica, que considera a relevância do contexto sócio-histórico para a compreensão de problemas da análise e da mudança social.

Destaca-se que a ACD tem sido potencialmente considerada e utilizada para a identificação, a apreciação e a reflexão dos elementos ideológicos que permeiam os discursos em relações e fenômenos sociais, principalmente aqueles que estão em posições hegemônicas (Rodrigues, 2009). Essa concepção teórico-metodológica emergiu, inicialmente, para trazer contribuições às teorias do campo da Linguística, mas, com o seu desenvolvimento, passou a estabelecer sinergias teóricas com as Ciências Sociais, a Filosofia da Linguagem, e a Linguística Sistêmica-funcional (Irigaray, Cunha, \& Harten, 2016), sendo incorporada até mesmo nos estudos organizacionais.

Por seu caráter transdisciplinar, a ACD não só oferece possibilidades de aplicações teóricas, como também operacionaliza e transmuta teorias, com vistas a uma abordagem sociodiscursiva dos fenômenos e dos fatos sociais (Ramalho, 2005). Nesse ínterim, Resende e Ramalho (2011) argumentam que essa vertente rompe 
fronteiras epistemológicas em favor da construção de uma abordagem sociodiscursiva, demonstrando a forma pela qual os discursos podem ser utilizados como modo de ação sobre o mundo e as pessoas.

Para a ACD, o discurso é o "uso da linguagem, seja ela falada ou escrita, vista como um tipo de prática social" (Fairclough, 2001, p. 28), que modifica a realidade, sendo por ela também modificado. Assim, ele não é entendido simplesmente como uma maneira de se comunicar, mas como uma prática que afeta e influencia a realidade, de tal modo que, "para entender a sociedade, é preciso entender o discurso que nela se produz e circula e, para entender o discurso, é preciso entender a sociedade que o constitui" (Irigaray et al., 2016, p. 3).

Em outras palavras, o meio dialógico é estabelecido por um processo que, se por um lado, tem as ações regidas por ferramentas discursivas; por outro, tais ações, discursivamente, representam o mundo social (Magalhães, 2005). Ademais, o discurso, além de histórico, é ideológico e constitui a sociedade, a cultura e suas relações de poder e de dominação. Como definiu Resende e Ramalho (2011), ele representa um elemento ao mesmo tempo estruturado e estruturante, sendo que, com isso, a análise do discurso é também uma análise de práticas sociais e discursivas, em contextos histórico-situacionais específicos.

Para a operacionalização da ACD, Fairclough (1989) estabelece um modelo tridimensional, posicionando o discurso em três dimensões analíticas: (1) o texto, que representa o núcleo do discurso, por meio da linguagem, compondo os diferentes discursos da sociedade; (2) a prática discursiva, que abarca o processo de produção, de distribuição e os consumos textual e discursivo, em um dado contexto; e (3) a prática social, constituída pelo conjunto de concepções ideológicas e hegemônicas que congregam as práticas discursivas e textuais.

Resende e Ramalho (2004), ao tratarem sobre essa análise tridimensional do discurso, indicam que a separação dos elementos tem somente função didática, visto que eles funcionam articuladamente, de maneira simultânea, na análise de discurso; todavia, é necessário compreender cada elemento, a partir de suas categorias analíticas (Figura 1). 
Discurso e Empreendedorismo Social: O que a Prática de Estudantes Engajados em Projetos Sociais pode Revelar?

\begin{tabular}{|c|l|l|}
\hline Dimensões & \multicolumn{1}{|c|}{ Descrição } & \multicolumn{1}{|c|}{ Categorias analíticas possíveis } \\
\hline Texto & $\begin{array}{l}\text { Linguagem contextualizada em um } \\
\text { evento discursivo, cujo foco de análise } \\
\text { se dá no sentido e na forma de } \\
\text { produção. }\end{array}$ & $\begin{array}{l}\text { Vocabulário, ordenação gramatical, } \\
\text { coesão textual e estrutura lexical. }\end{array}$ \\
\hline $\begin{array}{c}\text { Prática } \\
\text { discursiva }\end{array}$ & $\begin{array}{l}\text { Processos de produção, distribuição e } \\
\text { consumo dos textos. Interliga o texto à } \\
\text { prática social e se refere às ordens de } \\
\text { discurso presentes nos contextos } \\
\text { discursivos. }\end{array}$ & $\begin{array}{l}\text { (a) produção: intertextualidade e } \\
\text { (b) distribuição; } \\
\text { (c) consumo; } \\
\text { (d) força; } \\
\text { (e) presença e ausência de elementos; } \\
\text { (f) condições/coerência. }\end{array}$ \\
\hline Prática & $\begin{array}{l}\text { Práticas situacional, institucional e e } \\
\text { culturalmente } \\
\text { permeadas pelo pontextualizadas, e pela } \\
\text { ideologia. }\end{array}$ & $\begin{array}{l}\text { (a) ideologia: efeitos de sentido, } \\
\text { pressuposições, metáforas, molduras; } \\
\text { (b) hegemonia: orientações ideológicas, } \\
\text { econômicas, políticas e culturais; } \\
\text { (c) poder. }\end{array}$ \\
\hline
\end{tabular}

Figura 1 - Dimensões discursivas para Fairclough

Fonte: Adaptado de Fairclough (2001).

Como ilustra o quadro anterior, tem-se que a dimensão textual corresponde aos elementos pertinentes ao vocabulário, à gramática, à coesão e à estrutura textual. Nessa esfera, busca-se analisar de que forma os elementos textuais são organizados e combinados, e em que medida são estabelecidos os mecanismos coesivos, a seleção lexical, as construções sintáticas e a mobilização de argumentos que reproduzem os discursos hegemônicos (Resende \& Ramalho, 2004; Irigaray et al., 2016).

$\mathrm{Na}$ dimensão das práticas discursivas, estão a distribuição, a produção e o consumo do texto. Isso significa dizer que, nessa esfera, é observada a maneira pela qual o texto é tratado no processo comunicativo, ou seja, analisa-se a relação estabelecida entre o texto e o contexto que cercam o discurso (Andrade, Brito, Brito, \& Baeta, 2016).

Resende e Ramalho (2004), ao tratarem sobre a prática discursiva, apontam que ela deve contemplar a força dos enunciados, a coerência e as conexões com os pressupostos ideológicos, além de outros dois componentes: a intertextualidade (a relação entre o texto e os outros textos com os quais ele dialoga), e a interdiscursividade (a relação entre as ordens de discurso).

A dimensão da prática social identifica o discurso quanto às características ideológicas e hegemônicas, sendo que sua observação é realizada a partir de uma perspectiva macrossocial (Fairclough, 2001), isto é, da relação entre os níveis 
individual e universal dos discursos, em suas interconexões, revelando como os elementos constituintes são legitimados (Andrade et al., 2016). Assim, sob os aspectos: (a) da ideologia, deve-se levar em consideração os sentidos das palavras, as metáforas e as direções em que elas são conduzidas; e (b) da hegemonia: as orientações políticas, econômicas e culturais dos agentes (Resende \& Ramalho, 2004).

Em resumo, as dimensões do modelo tridimensional estão em íntima conexão: a prática textual deriva da representação e da representatividade dos interlocutores (prática discursiva), acarretando, por sua vez, a construção e a legitimação de ideologias e de tendências hegemônicas (prática social) (Irigaray et al., 2016). Então, "a distinção que se estabelece entre as dimensões é, sobretudo, de natureza teórica e metodológica" (Irigaray et al., 2016, p. 3), como já havia indicado Fairclough (2003). Esse fundamento sustenta, igualmente, o argumento de Resende e Ramalho (2004) sobre a linguagem (enquanto prática social) ser entendida como um modelo de ação historicamente situado, por meio da verificação das identidades, das relações e dos códigos que cercam o contexto social.

Tendo compreendido tais condicionantes da ACD, é necessário adentrar o discurso teórico sobre o Empreendedorismo Social, a fim de compor o debate que embasa este estudo.

\subsection{Empreendedorismo Social (ES) - conceitos e abordagens essenciais}

O ES, enquanto campo disciplinar, emerge no cenário dos anos de 1990, como uma abordagem em construção, mas com concepções teóricas próprias, sinalizando diferenças discursivas entre a gestão empreendedora tradicional e a gestão empreendedora social.

Acerca da concepção teórica tradicional, Schumpeter (1985) menciona que a prática empreendedora destrói a ordem econômica existente, por meio da introdução de novos produtos ou serviços, da criação de diferentes formas de organização e da exploração de novos recursos.

Em adição, Shane (2002) define o empreendedorismo como o estudo das fontes das oportunidades para a criação de algo novo, isto é: produtos, mercados, formas de organização e processos, incluindo os de descoberta, de exploração e de avaliação dos indivíduos que descobrem e exploram algo novo. 
Complementando a definição de empreendedorismo, Hisrich, Peters e Shepherd (2014) indicam que a ação de criar novos produtos ou de entrar em novos mercados pode ocorrer em organizações recém-criadas ou naquelas já estabelecidas. Constatase, então, por essa acepção, que o discurso teórico-conceitual sobre o empreendedorismo reforça as características hegemônicas de uma racionalidade instrumental, também tida como funcional, finalística e focada em resultados ou com fins calculados. Sendo assim, os aspectos econômicos devem ser também considerados, visto que quaisquer condutas e acontecimentos são, portanto, reconhecidos como meios para atingir determinadas metas. Em outras palavras, nessa racionalidade, a ação social se baseia no cálculo racional utilitário (Ramos, 1989; Thiry-Cherques, 2009; Bolis, Morioka, \& Sznelwar, 2017).

A noção discursiva do ES, por sua vez, caminha em outra perspectiva teórica, agregando valor à sociedade, com a oferta de soluções para problemas sociais e o intento de garantir a todas as pessoas uma qualidade de vida decente (Austin, Stevenson, \& Wei-Skillern, 2012; Rey-Marti, Ribeiro-Soriano, \& Palacios-Marqués, 2016).

Em termos práticos, entre os princípios do ES, está o desempenho de um papel que seria inicialmente atribuído ao Estado, pois envolve a realização de atividades para comunidades com escassez econômica, a fim de estimular a emancipação de seus integrantes, impactando seu desenvolvimento humano e social (Campos, Martens, Resende, Carmona, \& Lima, 2012).

Então, se o mercado e o próprio governo não atuam em prol do desenvolvimento social, torna-se necessário adotar projetos que busquem a melhoria de comunidades menos favorecidas (Oliveira, 2004; Keohane, 2012). Empreendedores sociais, consequentemente, assumem esse discurso e passam a ter como objetivo principal ajudar as pessoas e a sociedade, criando coletividade e implementando ações para garantir o autossustento e a melhoria contínua da comunidade (Silva, 2009).

Nesse sentido, o consenso discursivo na definição do ES está na essência do benefício social. Assim, os empreendedores sociais são agentes cuja visão está nas mudanças sociais, promovidas pela utilização de ferramentas de gestão, de inovação e, principalmente, de habilidades e de características como, por exemplo: determinação, liderança, envolvimento para realizar ações com valor social e que resultem em um alto impacto em toda uma população (Oliveira, 2004; Campos et al., 2012; Kedmenec et al., 2016).

Rev. de Empreendedorismo e Gest. Pequenas Empres. | São Paulo, v.9 | n.3 | p. 303-330 | Maio/Ago. 2020. 
Ao contrário da concepção tradicional, focada na racionalidade instrumental, o ES se pauta na lógica discursiva da racionalidade substantiva, cuja base são os valores, independentemente das expectativas de sucesso, não havendo qualquer ação humana interessada na consecução de um resultado posterior a ela. (Ramos, 1989; Thiry-Cherques, 2009). Portanto, a racionalidade substantiva é vista como uma ação orientada para o valor, baseada em padrões éticos (Bolis et al., 2017) e, por vezes, contra-hegemônicos, sem relação direta com o resultado final.

Para Oliveira (2004), um empreendimento social precisa apresentar algumas características fundamentais, como: (a) ser inovador; (b) ser realizável; (c) ser autossustentável; (d) envolver várias pessoas e segmentos da sociedade, principalmente a população atendida; e (e) provocar impacto social, permitindo que seus resultados sejam avaliados.

Austin et al. (2012) reforçam que o ES pode ser identificado em empresas privadas, organizações híbridas e do terceiro setor, e em grupos de pessoas unidas por uma causa e por um discurso comum (como é o caso do público discente, por exemplo). De acordo com Kedmenec et al. (2016), para os alunos praticarem o ES, é preciso que eles tenham disposição de sair da sala de aula e procurar problemas sociais em suas comunidades. Em termos de condições práticas, as universidades devem incentivá-los a se engajar em atividades voluntárias, a fim de que reconheçam os benefícios diretos que seus conhecimentos e suas habilidades podem propiciar às organizações. Ademais, eles são capazes de aprender, a partir da escassez de recursos, com a proposição de soluções para os problemas atuais, e por meio da combinação entre a lógica comercial e o bem-estar social.

Nesse sentido, entre os principais objetivos para um processo de aprendizagem, está o conteúdo aprendido e compreendido pelo discente, via professor (Rangel, 2010). Além disso, a teoria se torna mais significativa se a percepção da sala de aula estiver associada a um contexto (Candau, 2012), evidenciando que o ensino exige a consonância entre os atos e as formas de ensinar (Franco \& Pimenta, 2016). Portanto, a ação de ensinar é uma prática social, representada por diversas interações entre docentes, estudantes, instituição e sociedade, inseridas em contextos discursivos, socioculturais e históricos.

A esse respeito, Kedmenec et al. (2016) apontam que a educação em ES envolve a formação de profissionais capazes de conjugar competências de gestão e a preocupação com o impacto social. Para tanto, os cursos de ES devem aumentar a

Rev. de Empreendedorismo e Gest. Pequenas Empres. | São Paulo, v.9 | n.3 | p. 303-330 | Maio/Ago. 2020. 
conscientização dos estudantes sobre os diferentes problemas sociais, bem como desenvolver competências e confiança para que eles tomem a iniciativa de promover mudanças sociais, que, conforme Fairclough (2003), pedem transformações práticas e discursivas. As universidades, que desenvolvem uma educação voltada ao ES, são, por conseguinte, agentes de mudança e, ao mesmo tempo, formadoras de capital humano, capacitado e disponibilizado para transformar o mundo e enfrentar os desafios sociais (Shahverdi et al., 2018).

Especificamente no campo da Administração, Hopkins (2007) considera o aprendizado da temática uma oportunidade de ensino para criar redes de colaboração nas comunidades e auxiliar a formação de empreendedores sociais. No entanto, os cursos de ES, em universidades públicas brasileiras, ainda são incipientes, e dependem, também, do interesse dos alunos. Mesmo assim, algumas instituições utilizam a flexibilidade dos currículos para abordar temáticas sociais, de forma gradativa (Santos \& Galleli, 2013), utilizando-se da base teórico-prática do ES.

Além disso, os cursos de Administração estão cada vez mais voltados à formação de administradores que sejam líderes comprometidos com as causas sociais e capazes de atuar em contextos socioeconômicos menos favorecidos (Oliveira et al., 2014; Kedmenec et al., 2016). Isso porque empresas de diversos setores estão investindo em projetos e na gestão social e/ou sustentável de seus negócios.

Portanto, mais do que um conhecimento teórico e uma concepção de ensinoaprendizagem, o ES é uma prática discursiva, que rompe com as concepções ideológicas e hegemônicas no campo da Administração, focalizando novas compreensões em torno de uma gestão transformadora, articulada e convergente com os valores sociais e coletivos das comunidades.

\section{PROCEDIMENTOS METODOLÓGICOS}

Em termos teórico-metodológicos, este estudo é qualitativo-descritivo, pois qualifica e descreve experiências e práticas sociais e discursivas resultantes do engajamento em projetos sociais dos estudantes de Administração. Devido à base crítico-analítica para a interpretação das concepções discursivas sociais, o estudo está pautado na ACD, sendo os interlocutores dos discursos investigados os estudantes que cursaram a disciplina de Empreendedorismo Social, na Universidade Federal de Itajubá (Unifei), sediada na região sul do estado de Minas Gerais, entre os 
anos de 2013 e 2017. Vale salientar que a disciplina de Empreendedorismo Social é ministrada no primeiro semestre de cada ano letivo, para estudantes matriculados no $5^{\circ}$ período, sendo que uma das atividades consiste em desenvolver um projeto de ES para instituições sem fins lucrativos da comunidade local.

O processo de coleta dos discursos se deu por meio de entrevistas, realizadas com os estudantes dispostos a participar da pesquisa. Houve, então, um contato prévio com esse público, para a seleção e a divisão dos participantes em dois grupos focais, de acordo com o aproveitamento acadêmico no projeto social da disciplina, tendo sido escolhidos: (1) aqueles com aproveitamento superior; e (2) os com baixo aproveitamento.

Destaca-se que esse critério foi estabelecido como tentativa de compreender as concepções discursivas de ambos os grupos, e de averiguar as narrativas, as ideologias e os discursos dominantes. Por essa razão, a divisão foi feita entre os interlocutores que tiveram, comparativamente, maior e menor aproveitamento acadêmico, com a finalidade de evidenciar se o êxito na disciplina de ES reflete nuances de racionalidades relativamente mais subjetivas e voltadas ao âmbito social, ou, em caso contrário, se não houve qualquer efeito, na prática ou no discurso dos alunos.

Ademais, a opção por investigar esses dois grupos focais pretende provocar reflexões acerca da importância da oferta de disciplinas que despertem o entendimento das ações de geração de valor, não somente mercadológico, mas social e humanitário (Oliveira, 2004; Campos et al., 2012; Kedmenec et al., 2016), sobretudo nos cursos de Administração.

A composição do grupo focal com alto aproveitamento acadêmico abarcou os estudantes que se posicionaram entre os três melhores grupos com maior comprometimento na disciplina. Dez estudantes foram, então, contatados por e-mail e, desses, nove aceitaram participar do processo investigativo. Eles pertenciam a variados grupos de trabalho, que realizaram a disciplina em períodos diferentes (nos anos de 2015, 2016 e 2017).

O grupo de estudantes com baixo aproveitamento acadêmico também foi contatado por e-mail. $\mathrm{O}$ critério de escolha apontou para o posicionamento entre os três últimos grupos de menor comprometimento na disciplina. Dos 24 alunos contatados, oito quiseram participar da pesquisa, porém, apenas quatro compareceram ao grupo focal. Eles também fizeram parte de diferentes grupos de

Rev. de Empreendedorismo e Gest. Pequenas Empres. | São Paulo, v.9 | n.3 | p. 303-330 | Maio/Ago. 2020. 
trabalho e cursaram a disciplina em períodos diversos (entre os anos de 2013, 2015 e 2017). Cabe mencionar que ambos os grupos focais aconteceram no primeiro semestre de 2018, na própria universidade, em dias e horários previamente definidos.

Como instrumento de coleta dos discursos, adotou-se um roteiro de entrevista semiestruturado, contendo questões que elucidavam a experiência de ter participado da disciplina de Empreendedorismo, incluindo as facilidades e as dificuldades ora vivenciadas. Juntamente à prática das entrevistas, foram realizadas observações do processo de produção dos discursos, considerando os modos de linguagem verbal e não verbal. De acordo com Fairclough (2001), durante o processo de pesquisa, emergem elementos essenciais do discurso, como a linguagem, a fala, a entonação, as pausas e os momentos de silêncio, bem como a linguagem corporal e o não discurso, além das escolhas gramaticais. Portanto, durante a narrativa dos estudantes, um dos pesquisadores permaneceu em processo de observação, fazendo as anotações necessárias no diário de campo.

Desse modo, os grupos focais oportunizaram a reflexão sobre a experiência vivida. O espaço discursivo permitiu revelar significados e fez emergir indagações relacionadas às diferenças vivenciadas pelos estudantes. As produções discursivas foram gravadas em áudio, com o consentimento dos estudantes e, posteriormente, o material foi transcrito, para proceder à análise tridimensional do discurso.

O corpus de análise envolveu, então, os grupos focais, a descrição dos discursos emitidos e as observações. Ademais, é importante ressaltar que, para preservar a identidade dos estudantes, eles receberam os códigos G1.1 a G1.9, para o primeiro grupo; e G2.1 a G2.4 para o segundo grupo, conforme a ordem de aceitação em participar da pesquisa.

A análise tridimensional do discurso foi realizada com base nas dimensões de produção das práticas (textuais, discursivas e sociais); e a operacionalização da ACD se deu a partir dos grupos focais, das observações do pesquisador e da descrição dos discursos emitidos. Foram priorizados, como sugere Fairclough (2003), os aspectos discursivos sociais, em detrimento dos aspectos linguísticos, haja vista a natureza da pesquisa e a sua contribuição para as ciências sociais.

$\mathrm{Na}$ análise, foram considerados as escolhas gramaticais, a força dos enunciados, o estilo discursivo, as expressões, o tom de voz, a ironia e a satisfação com que eram produzidos os discursos, intentando compreender as práticas discursivas e sociais dos estudantes. Essa orientação analítica permitiu compreender

Rev. de Empreendedorismo e Gest. Pequenas Empres. | São Paulo, v.9 | n.3 | p. 303-330 | Maio/Ago. 2020. 
as experiências, as intertextualidades e as interdiscursividades dos discursos produzidos, bem como favoreceu a identificação das concepções ideológicas e hegemônicas que permeiam esse campo de estudos.

\section{ANÁLISE DISCURSIVA DAS ENUNCIAÇÕES - O QUE OS DISCURSOS REVELAM SOBRE A EXPERIÊNCIA COM O EMPREENDEDORISMO SOCIAL?}

Para cumprir os objetivos, optou-se por discorrer sobre a experiência dos estudantes, conjecturando: (1) a prática discursiva dos discursos predominantes; (2) a presença textual do discurso gerencial hegemônico da Administração; e (3) as dificuldades enfrentadas na prática social.

Vale lembrar que a ACD admite certa relativização dos dados, em processos de análise (Fairclough \& Wodak, 1997), permitindo aos pesquisadores fazer escolhas de textos, conforme os interesses do estudo. Assim, foram selecionados os trechos das falas dos estudantes que melhor ilustraram as experiências investigadas em torno da prática empreendedora de projetos sociais.

Ao desvelar discursivamente as vivências dos estudantes, alguns elementos se destacaram pelo efeito de sentido provocado, como: "Pra gente, foi sensacional" (G1.7); "é muito gratificante" (G1.2); "A gente se sente poderoso, assim, de poder chegar (...)" (G1.1); "é uma realização tremenda, porque 'cê' acha que é impossível" (G1.8). Os termos e expressões - propositadamente destacados em negrito, a fim de enfatizar a produção de sentidos discursivos - remetem a adjetivos relacionados à grandiosidade (tremenda), empoderamento (poderoso), e emoção (sensacional, gratificante), possibilitando, portanto, a interpretação de que os estudantes do primeiro grupo focal (com melhor aproveitamento acadêmico na disciplina de ES) percebem as experiências vivenciadas como positivas, causando, inclusive, sentimentos de emoção, reforçados pela entonação das vozes.

Para externalizar essas expressões, foi unânime a linguagem corporal de satisfação: eles emitiam sorrisos, gestos e olhares, que denotavam quão enriquecedora tinha sido a experiência em contribuir com o meio social, de forma empreendedora.

No segundo grupo focal (com baixo aproveitamento acadêmico), os trechos discursivos de destaque foram: "Então foi bem legal" (G2.1); "Eeee, é bem... foi bem difícil, mas foi bem legal” (G2.2); "é muito difícil, é muito difícil dar cem por cento de si quando 'cê' não ganha nada pra fazer" (G2.3). Pelo estilo discursivo adotado, 
constata-se que a experiência desses estudantes foi interessante, embora marcada por dificuldades.

É notório que os grupos de estudantes apresentam percepções e linguagens diferentes, relacionadas com os resultados práticos das experiências vivenciadas. Os estudantes G2.1 e G2.2 empregaram o objeto discursivo "bem legal", que remete a uma percepção positiva das experiências vivenciadas, porém, se comparado aos adjetivos utilizados pelos interlocutores do primeiro grupo focal, ele denota menor intensidade.

No caso do estudante G2.3, sua percepção foi de dificuldade, enfatizada pelo emprego do advérbio de intensidade "muito", ao indicar que o projeto social aconteceu em uma escola municipal, sem ter retorno financeiro. O pano de fundo desse argumento discursivo denota interdiscursividades ideológicas, consumidas no campo da Administração, que remetem à lógica do lucro e de ganhos de capital nas transações. Nesses termos, há a reprodução do discurso e da prática dominante sobre a lucratividade, além da ideologia que envolve a racionalidade instrumental ou funcional (Ramos, 1989; Thiry-Cherques, 2009; Bolis et al., 2017). Tal situação enfatiza a afirmação de Aktouf (2004) sobre o grande desafio dos cursos de Administração em formar profissionais reflexivos, críticos e preparados para lidar com a complexidade da vida social.

Outro ponto que merece destaque se relaciona aos efeitos de sentido e aos estilos de linguagem utilizados por cada grupo para comunicar suas concepções discursivas. No primeiro grupo, a entonação da voz é diferenciada, traz animação, vibração, euforia e sentimentalidades. As falas dos estudantes recorrentemente se atropelavam, na euforia de complementar, somar e reforçar, de modo que, quando um enunciava alegria e prazer, como sentimento resultante da experiência no projeto social, os demais expressavam conformidade e concordância, balançando afirmativamente a cabeça, sorrindo, e emitindo olhares de aprovação e de compartilhamento.

De acordo com Fairclough (2001), a produção discursiva é constrita de argumentos, ordenados por recursos linguísticos e por estilos, que reforçam, confirmam e contradizem discursos já enunciados. Nos casos relatados, mais do que a tentativa de reforço do discurso, houve a confirmação da prática declarada.

No segundo grupo, em contrapartida, a entonação das vozes não demonstra entusiasmo e satisfação, tampouco compartilhamento de sentimentos, pois enquanto 
um falava, os outros apenas escutavam, sem interagir. Foi perceptível o nervosismo no tom das vozes e nos gestos, bem como o desconforto em relembrar a experiência. Portanto, não apenas o discurso oral diferenciou os grupos, mas todo o conjunto da linguagem proferida: enquanto o primeiro grupo focal externalizou um discurso coletivo de positividades, o segundo emitiu discursos isolados, focalizados em desejos individuais.

O estudante G1.7 argumenta essa percepção e a preocupação com os aspectos coletivos, ao dizer: "A hora que você entrega e viu que tá pronto... não só a realização de estar pronto, mas de ter impactado e significado pra alguém, é gratificante". Para o estudante G1.1, depois de ter cursado a disciplina de Empreendedorismo e realizado o projeto, ele passou a se preocupar em desenvolver "o ambiente ao meu redor, as pessoas ao redor, me preocupar mais com isso, que... antes parecia que eu não me preocupava com isso". Essas percepções ressaltam a proposta de Candau (2012), de que a teoria, quando associada a um contexto, torna-se mais significativa. Além disso, tais produções provocam efeitos de sentido de mudança prática e de transformação social.

O estudante G1.2 declara que um dos pontos mais marcantes da sua experiência, na disciplina, foi se deparar "com uma realidade muito diferente da nossa e aí é um mundo que, às vezes, a gente não enxerga, né?". Ao usar as expressões "nossa" e "a gente", o estudante profere o seu discurso no coletivo, como se estivesse falando em nome de todo o grupo. E, ao ouvir isso, os demais consentem, com gestos e olhares. O estudante evidencia, em seu discurso, uma epifania: por meio da disciplina de ES, outra realidade, antes desconhecida, foi descortinada, revelada e notada. A expressão "a gente não enxerga" denota uma cegueira, em termos de prática discursiva, que os estudantes assumem, mesmo quando reconhecem a realidade.

De modo geral, essa percepção permite atestar a importância da oferta, pelos cursos de Administração, da disciplina de ES, com fins de oportunizar aos estudantes experiências em contextos diversos, voltados, por exemplo, ao desenvolvimento da consciência social (Oliveira et al., 2014; Kedmenec et al., 2016; Shahverdi et al., 2018).

Ainda considerando a percepção dos aspectos coletivos, nas experiências vivenciadas pelos no primeiro grupo focal, o estudante G1.4 destaca que "às vezes, alguma coisa pequena que a gente faz, é um grande avanço pra eles (...) doação, 
alguma coisa, assim, que a gente nem precisava, pra eles já foi um... um ganho enorme." Ele utiliza dois adjetivos (grande e enorme), que denotam tamanho, mas foram empregados com sentido conotativo, para enfatizar os resultados positivos e os benefícios em profundidade para o campo da sua atuação, bem como dos membros do seu grupo, no contexto social em que estiveram inseridos naquela ocasião - no caso, uma instituição cuidadora de idosos.

Os estudantes G1.2, G1.4 também enunciam, no coletivo e na argumentação, as ordens de discurso demarcadas na prática social, que elucidam a noção teórica e conceitual do ES. Isso corrobora a afirmação de Oliveira (2004) e Campos et al. (2012), sobre a relação entre o ES e o benefício social.

No segundo grupo focal, não foi observada a preocupação com o coletivo, tampouco com o âmbito social, mas tiveram destaque os aspectos formais do desenvolvimento do projeto da disciplina de ES, como as dificuldades no planejamento, e as questões concernentes à racionalidade funcional, especificamente a falta de motivação, por não ter um retorno financeiro pelo trabalho, como indica um dos trechos:

\footnotetext{
"A gente começava a construir um tanto de coisa, mas a gente não sabia de fato pra onde que a gente tava indo, eu acho que isso é o lance de qualquer empreendedor, qualquer empreendimento que cê vai fazer, é difícil 'cê' ter um objetivo, é difícil você tá na frente do negócio e ficar pensando: 'Pra onde que a gente vai agora?'. Foi difícil ter esse direcionamento. Uma coisa que faltou pra mim também foi motivação. Fazer um trabalho de graça é muito difícil ...". (G2.3)
}

Discursos, como o transcrito anteriormente, evidenciam que não foi efetivada, para alguns estudantes, a oportunidade de formação profissional crítica, reflexiva e preocupada com o social, como afirma Aktouf (2004), proporcionada pela disciplina de Empreendedorismo Social. Isso se dá porque a leitura do projeto foi rasa, em termos de seus impactos e das possíveis contribuições para uma prática social transformadora. Trata-se da lógica discursiva do empreendedorismo gerencial e hegemônico da Administração, não do social. Além disso, a ausência de "motivação" financeira, apontada na fala, reforça claramente o discurso pautado na premissa de eficiência e de maximização de lucros, ao invés de valores sociais e humanos, como destacam Aktouf (2004) e Oliveira et al. (2014).

O aspecto financeiro, ainda dominante na sociedade e no meio acadêmico, também é ressaltado pelo estudante G2.4, que recorre à interdiscursividade, ou seja, o seu discurso se relaciona com o do estudante G2.3, ao enfatizar "mas o que 'cê' 
falou é verdade". Ele reproduz, assim, o mesmo discurso dominante do colega, acerca da questão financeira, deixando subentendidas como falsas as percepções diferentes, dos estudantes do primeiro grupo focal, que destacam a importância dos aspectos sociais. A prática social desses estudantes reflete explicitamente os discursos gerenciais, consumidos por meio de ideologias, e as ordens de discursos hegemônicas, atinentes ao mainstream da Administração.

Ao discorrer sobre a sua experiência em uma instituição de tecelões, o estudante G2.4 dá ênfase, assim como os dois colegas mencionados anteriormente, a uma visão gerencial, sem focar nos aspectos sociais. Ele diz que as pessoas, inseridas no contexto em que o projeto da disciplina de Empreendedorismo Social foi desenvolvido, estavam acostumadas com o "assistencialismo", mas que a função deles (estudantes) era a de administradores: "a nossa função lá, até enquanto administradores". Com essa narrativa, subentende-se que não é função do administrador prestar assistência ao meio social, denotando uma compreensão racional, limitada e instrumental do papel desse profissional, na sociedade em que ele se insere.

Essas três últimas concepções discursivas evidenciam que o ensino da Administração continua voltado mais às premissas de eficiência e de maximização de lucros do que aos valores sociais e humanos. Poucos são os cursos e as universidades que oferecem disciplinas com a abordagem de temáticas sociais na formação dos administradores. Isso indica que o assunto ainda não é prioritário ou fundamental nesse curso de graduação, no país (Aktouf, 2004; Oliveira et al., 2014; Shahverdi et al., 2018). Ressalta-se, também, que, mesmo quando são ofertadas disciplinas que englobam tal temática, como a de ES, alguns estudantes se mostram incapazes de pensar de forma reflexiva e crítica, pois mantêm o foco na visão tradicional e continuam reproduzindo os discursos dominantes.

De acordo com Fairclough (2003), existe a tendência de que os textos e as práticas discursivas e sociais dos agentes reflitam as ideologias e as ordens de discurso hegemônicas do campo. Para Santos e Galleli (2013), o ensino do ES, na Administração, ainda está em sua infância, nas universidades públicas brasileiras, sendo que essa formação depende também do interesse dos estudantes.

Diante do exposto, é possível ressaltar a importância de os estudantes saírem da sala de aula, em busca por soluções para os problemas sociais de suas comunidades; e de as universidades os incentivar no engajamento em atividades 
voluntárias, para reconhecerem que muitas organizações podem se beneficiar diretamente de seus conhecimentos e de suas habilidades (Kedmenec et al., 2016).

Isso pode levar a uma mudança prática, do discurso social (voltado a uma racionalidade instrumental) para o discurso social (fundamentado na racionalidade substantiva). A disciplina de ES, ofertada no curso de Administração da Unifei, é um exemplo de incentivo a essa mudança. Para tanto, é preciso que os estudantes estejam dispostos e, principalmente, exerçam a reflexividade, o pensamento crítico e o seu papel socioprofissional, apresentando, assim, novos discursos.

As discrepâncias nas percepções discursivas dos grupos focais reforçam os diferentes modos de envolvimento acadêmico dos estudantes na disciplina de ES. O grupo com alto aproveitamento vivenciou o projeto e experimentou diferentes sensações racionais substantivas, o que proporcionou o envolvimento na sociedade e a identificação de valores inseridos nos diferentes contextos sociais dos quais participaram. O grupo focal com baixo aproveitamento, por sua vez, não conseguiu finalizar o projeto, nem mesmo como estratégia discursiva, optando por apontar as dificuldades na sua realização e a inadequação do planejamento, para alcançar os resultados esperados, em vez de assumir a sua falta de engajamento nessa prática.

Para avançar nesse debate, na sequência, estão apontadas dificuldades específicas, vivenciadas ao longo do processo.

\subsection{Dificuldades vivenciadas}

Os participantes dos dois grupos focais foram questionados sobre as principais dificuldades sentidas no processo de inserção em uma comunidade, representada, neste estudo, pela vivência em um projeto social.

Nos discursos dos estudantes com alto aproveitamento acadêmico na disciplina de ES, essas dificuldades se manifestaram por meio de termos ou expressões-chave, como: "tempo", "inexperiência", "várias equipes fazendo", e "conseguir fundos", conforme ilustram os trechos, a seguir, dos discursos dos estudantes G1.2 e G1.9.

De acordo com o estudante G1.2, "uma coisa que dificulta é o fato de ter várias equipes fazendo. Então na hora que você vai pedir ajuda a pessoa já deu pra outra equipe, e isso é muito difícil. É um ponto que dificulta muito o trabalho". O motivo atribuído à dificuldade está relacionado, então, à competição, bastante enfatizada nos cursos de Administração, base das pressuposições de empreendedor de Schumpeter (1985), e que se mostra presente no contexto do ES. Essa mesma dificuldade é 
enfatizada pelo emprego, duas vezes, do advérbio de intensidade "muito". O discurso também sublima uma crítica à escassez de agentes dispostos a contribuir com doações para órgãos, entidades, instituições e pessoas necessitadas.

O estudante G1.9, por sua vez, enfatizou "o tempo e a inexperiência, a gente tinha três meses pra planejar e executar e encerrar o projeto. E desde a parte do principal era conseguir fundos, o nosso, principalmente, precisava de muito dinheiro". O tempo reduzido para promover as ações idealizadas pelo grupo também é apresentado como uma dificuldade, reforçada pelo argumento dos demais estudantes do grupo, que indicaram a necessidade de extensão do projeto, para que eles pudessem contribuir ainda mais com as instituições escolhidas.

Embora a busca por recursos financeiros possa remeter a uma visão da lógica produtiva, reproduzindo um dos ideários do mercado, ainda enfatizado pelas universidades, segundo Chauí (2001), é preciso considerar o contexto em que ela está inserida. Essa, aliás, é uma das ordenações basilares da ACD, de acordo com Resende e Ramalho (2011). Nesse caso, o estudante precisava buscar recursos para atender às demandas financeiras de uma instituição de assistência a idosos, em sua região, e o seu comprometimento, juntamente com o de seu grupo, proporcionou, de fato, melhorias à instituição. Conseguir fundos, então, nesses termos, significa contribuir de forma mais efetiva para a resolução de problemas institucionais.

Dificuldades como as apontadas pelo estudante G1.9 poderiam implicar em uma visão negativa da experiência vivenciada, mas, como ilustra o estudante G1.5, também discorrendo sobre os recursos financeiros, elas foram vistas como positivas: "essa questão dos fundos é um ponto de dificuldade, mas acaba forçando você a ser mais ainda criativo, que é um ponto positivo". Para mostrar sua percepção, ele recorre à conjunção coordenativa adversativa "mas", evidenciando uma oposição entre a "dificuldade" e o "ponto positivo". Trata-se de uma estratégia de linguagem, que provoca efeitos de sentido, em que a dificuldade vivenciada no processo é justificada pelo aprendizado criativo, que se revela nessa dinâmica.

Outros dois estudantes, G1.1 e G1.4, também atribuem uma visão positiva às dificuldades: "ao mesmo tempo em que é um ponto de dificuldade é um ponto... um ponto positivo" (G1.1).

Para reforçar tal percepção, o estudante recorre ao termo "dificuldade" e à expressão "ponto positivo", como se fossem opostos, mas percebidos concomitantemente.

Rev. de Empreendedorismo e Gest. Pequenas Empres. | São Paulo, v.9 | n.3 | p. 303-330 | Maio/Ago. 2020. 
No caso do estudante G1.4, que diz: "fica como aspecto positivo. Porque aí você tem que correr atrás, fazer um networking, procurar as coisas", tais constatações permitem compreender a concordância quanto ao impulso dado pelas dificuldades à busca de realização das atividades para finalizar o projeto. Isso é enfatizado pelo emprego conotativo da expressão "correr atrás", que, nesse contexto, significa buscar aquilo que é necessário para alcançar os objetivos traçados. É empregado, também, o termo da língua inglesa "networking", muito utilizado nos cursos de Administração, especificamente no que tange ao empreendedorismo, remetendo ao estabelecimento de uma rede de contatos.

Os discursos trazem, portanto, interdiscursividades e intertextualidades, consumidas no discurso gerencial da Administração, haja vista que são enunciadas várias expressões características da área. Todavia, em sentidos e contextos que focalizam mais os resultados substantivos do que propriamente os instrumentais. Ademais, a enunciação do estudante G1.4 permite interpretar que, no caso do projeto desenvolvido por ele e seu grupo, na mesma instituição de idosos de G1.9, foi importante o contato com outras pessoas, como patrocinadores, pedreiros, pintores e gestores da própria instituição, que puderam auxiliar no enfrentamento das dificuldades, ao longo do desenvolvimento do projeto.

O envolvimento de outras pessoas é também ressaltado pelo estudante G1.1 "'cê' envolve gente que 'cê' nem imagina", que atuou em uma escola da rede municipal de ensino. O "envolvimento de pessoas" aparece nos discursos como um recurso de linguagem que justifica as dificuldades apresentadas. De acordo com Fairclough (2001), as escolhas textuais e argumentativas conferem efeitos de sentido diversos, conforme cada estrutura discursiva. Além disso, o envolvimento de terceiros corrobora a visão de Shahverdi et al. (2018) sobre o ES ser capaz de proporcionar soluções efetivas para diversos problemas sociais, econômicos e ambientais, por meio da atuação de diferentes agentes, preocupados com as mazelas sociais (Shahverdi et al., 2018). Em termos práticos, tal envolvimento solucionou problemáticas tangíveis, como a falta de uma biblioteca em uma escola municipal, e a reforma de um forro, em uma instituição de idosos, solucionando os problemas sociais existentes.

No segundo grupo focal, composto por estudantes que obtiveram baixo aproveitamento acadêmico na disciplina de ES, são colocadas como dificuldades percebidas os aspectos pontuais do processo de planejamento: "ponto negativo foi falta de planejamento, bastante, a gente não tinha um cronograma" (G2.1). Nesse 
caso, a dificuldade é considerada um ponto negativo, enfatizado pelo emprego do adjetivo "bastante", que transmite a ideia de maior intensidade. A dificuldade é associada à falta de estabelecimento, pelo grupo, de um cronograma para cumprir as atividades necessárias à realização do projeto. Ao que parece, existe uma tentativa de justificar a falta de engajamento e a não entrega de um resultado positivo pelo discurso da negação de condições operacionais, como: falta de planejamento e falta de cronograma - elementos que constituem ordens do discurso gerencialista no campo da Administração.

O estudante G2.2 destaca que, no caso do seu grupo, que atuou em uma instituição de proteção de animais, houve: "falta de planejamento demais, ficou $80 \%$ do tempo muito teórico, muito "vamos fazer"? Tem que fazer, tem que fazer", aí na hora que viu faltava um mês, três semanas". Para enfatizar a falta de planejamento, o estudante recorre ao emprego do advérbio de intensidade "demais". Parte dessa falta de planejamento é explicada pela ausência de ações concretas, expressa na fala do estudante: " $80 \%$ do tempo muito teórico". O termo teórico é empregado de maneira conotativa, para predizer ações que ficaram apenas no plano das ideias, sem serem concretizadas. Além disso, o estudante recorre à intertextualidade, manifesta para enfatizar que ficaram falando em algo para ser feito, mas que não foi. Aqui, ele traz as vozes dos demais estudantes envolvidos para instituir a sua crítica e culpabilizar os outros pelos resultados entregues.

Franco e Pimenta (2016) apontam que o ensino exige uma consonância nos atos e nas formas de ensinar, contudo, conforme Santos e Galleli (2013), para que isso ocorra, há dependência do interesse dos estudantes. E, no caso específico anteriormente mencionado, esse "interesse" não se evidenciou como uma prática discursiva, por parte dos estudantes do segundo grupo focal.

As dificuldades apontadas reforçam uma visão mais gerencialista, se comparadas às percepções dos estudantes do primeiro grupo focal, focada no planejamento e pautada em premissas de eficiência de processos, como destaca Aktouf (2004). Entretanto, nem todos os estudantes do segundo grupo focal tiveram essa visão gerencialista, voltada para a racionalidade instrumental, abordada por autores, como: Ramos (1989), Thiry-Cherques (2009), e Bolis et al. (2017).

O estudante G2.3 afirma que, embora tenham existido dificuldades, "um aprendizado valioso que a gente teve foi sair daquela lógica assim, empresarial, para um negócio social, eu acho que isso foi uma quebra (...) essa experiência que a gente

Rev. de Empreendedorismo e Gest. Pequenas Empres. | São Paulo, v.9 | n.3 | p. 303-330 | Maio/Ago. 2020. 
tem, faz a gente refletir bastante sobre a nossa vida". Ao empregar a expressão "a gente", ele assume que todos do seu grupo tiveram a mesma percepção, porém essa pode ser uma afirmação errônea, já que os demais não compactuaram com esse discurso. Cabe situar, ainda, que o estudante só apresenta essa visão ao final dos questionamentos, quando é convidado a refletir sobre os sentimentos resultantes de sua prática. Ele emprega o adjetivo "valioso" para se referir à aprendizagem proporcionada pela mudança ("quebra") de uma "lógica, assim, empresarial”, para um "negócio social".

A mudança supracitada envolve a passagem de uma racionalidade instrumental a uma racionalidade substantiva (Bolis et al., 2017). Assim, há uma corroboração da afirmação de Shahverdi et al. (2018) sobre as universidades, que desenvolvem a educação para o ES, não desempenharem apenas o papel de agentes de mudança, mas de também desenvolverem o capital humano, capaz de ser utilizado para transformar o mundo e enfrentar os desafios sociais. Esse desenvolvimento pode ser observado na fala do estudante G2.3, por meio da reflexão (enfatizada pelo adjetivo "bastante") acerca da transformação ocasionada na sua vida.

As análises feitas nesta seção também evidenciaram, entre os grupos focais investigados, concernentes à percepção discursiva e à prática social. O grupo com alto aproveitamento acadêmico percebeu nas dificuldades, oportunidades de aprendizado e de crescimento pessoal; o outro grupo, em contrapartida, identificou barreiras não transpostas. Nesse diapasão, constata-se que os discursos emitidos, de modo geral, com a exceção de algumas restrições, permitiram aos estudantes a ressignificação de suas práticas, relativas ao ES. Isso é comprovado quando a pesquisadora desliga o gravador e dois, dos estudantes do segundo grupo focal, reportam-se a ela, dizendo que se arrependeram de não ter aproveitado melhor aquela oportunidade de aprendizagem.

\section{CONSIDERAÇÕES FINAIS}

Este estudo, conforme sugere Fairclough (2003), tratou os discursos dos estudantes como práticas sociais e como a materialização de suas ações por meio da realização dos projetos sociais na disciplina de Empreendedorismo Social, do curso de Administração da Unifei, de Minas Gerais.

Os resultados apontaram que as concepções discursivas externalizadas refletem a prática discursiva do ES e de seus valores coletivos, mas, ao mesmo tempo, 
demarcam o discurso gerencial hegemônico da Administração e a sua lógica instrumental.

Tais constatações se devem ao fato das escolhas em torno dos sujeitos de análise, pois foram agrupados estudantes, de acordo com o grau de aproveitamento acadêmico, apresentado na estratégia de ensino-aprendizagem da disciplina, e o resultado do projeto social empreendido. Acredita-se que essa escolha favoreceu o aparecimento de discursos diferentes entre os dois grupos focais.

Acerca da experiência vivenciada, percebeu-se a presença de discursos antagônicos: o primeiro grupo focal retrata a experiência com intensidade e grandeza; já o segundo, ressalta a dificuldade. O predomínio do discurso do primeiro grupo se pautou em uma lógica discursiva fundamentada na racionalidade substantiva; enquanto o segundo esteve centrado em uma lógica instrumental.

No que se refere às dificuldades enfrentadas, igualmente, há discursos contraditórios: o primeiro grupo relata as dificuldades, seguidas da percepção positiva por elas oportunizadas; já o segundo grupo, ateve-se às dificuldades funcionais de planejamento dos grupos. Um ponto comum é que os grupos, apesar de algumas denotações contraditórias, reconhecem as oportunidades de reflexão proporcionadas pela disciplina, pois, em vários momentos, os discursos, principalmente dos estudantes do primeiro grupo focal, apontavam para mudanças práticas e discursivas, a partir da experiência com o ES.

Em síntese, cabe apontar que a hegemonia do discurso instrumental não aparece em todos os grupos. O primeiro grupo relata a experiência com emoção, intensidade e se baseia em valores pautados na racionalidade substantiva e na relevância do projeto para o bem coletivo. Essa perspectiva demonstra o quão a prática discursiva está sujeita a remodelações, a partir de experiências e contextos diferentes, fato que corrobora as críticas de vários autores acerca da mudança discursiva na formação do administrador.

Como propostas para trabalhos futuros, evidencia-se a necessidade de entender os sentidos apreendidos pela experiência e de desvelar os significados do aprendizado para os estudantes, cujas experiências acontecem fora do mainstream da Administração e antes da imersão nessa vivência. É relevante também analisar as concepções discursivas dos estudantes, a fim de investigar os motivos que os levaram ao baixo e ao alto aproveitamento acadêmico. Por fim, acredita-se na necessidade da adoção, pelos meios acadêmicos, de práticas transformadoras de ensino e de

Rev. de Empreendedorismo e Gest. Pequenas Empres. | São Paulo, v.9 | n.3 | p. 303-330 | Maio/Ago. 2020. 
aprendizagem, permitindo, com isso, aos estudantes, a (re)invenção dos significados ideológicos e hegemônicos do discurso construído no campo da gestão.

\section{REFERÊNCIAS}

Aktouf, O. (2004). Pós-globalização, administração e racionalidade econômica: a síndrome do avestruz. São Paulo: Atlas.

Andrade, L. P., Brito, M. J., Brito, V. G. P., \& Baeta, O. V. (2016). Estratégia como prática: uma análise das práticas ambientalistas da Universidade Federal de Lavras (UFLA). Revista de Gestão Social e Ambiental, 10(2), 2-18.

Austin, J., Stevenson, H., \& Wei-skillern, J. (2012). Social and commercial entrepreneurship: same, different, or both? Revista de Administração, 47(3), 370-384.

Bolis, I., Morioka, S. N., \& Sznelwar, L. I. (2017). Are we making decisions in a sustainable way? A comprehensive literature review about rationalities for sustainable development. Journal of Cleaner Production, 145, 310-322.

Campos, T. M., Martens, C. D. P., Resende, M. R., Carmona, V. C., \& Lima, E. (2012). Produção científica brasileira sobre empreendedorismo social entre 2000 e 2012. Revista de Empreendedorismo e Gestão de Pequenas Empresas, 1(2), 60-89.

Candau, V. M. (2012). A didática e a formação de educadores - da exaltação à negação: a busca da relevância. 33a ed. Petrópolis: Vozes.

Chauí, M. S. (2001). Escritos sobre a universidade. São Paulo: Unesp.

Fairclough, N. (1989). Language and power. London: Longman.

Fairclough, N. (2001). Discurso e mudança social. Brasília: Editora da UnB.

Fairclough, N. (2003). Discurso e mudança social. In Magalhães, I. (Org.). Brasília: Universidade de Brasília.

Fairclough, N., \& Wodak, R. (1997). Critical discourse analysis. In Van Dijk, T. A. (Ed.). Discourse as social interaction (pp. 258-284). London: Sage.

Faria, J. H., \& Meneghetti, F. K. (2010). (Sem) saber e (com) poder nos estudos organizacionais. Cadernos EBAPE.BR, 8(1), 38-52.

Franco, M. A. S., \& Pimenta, S. G. (2016). Didática Multidimensional: Por uma Sistematização Conceitual. Educação e Sociedade, 37(135), 539-553.

Hisrich, R., Peters, M., \& Shepherd, D. (2014). Empreendedorismo. 9a ed. Porto Alegre: AMGH.

Hopkins, D. (2007). Social entrepreneurship: "real world" activations of the liberal arts education. Recuperado de http://sites.middlebury.edu/middlab/files/2011/01/DavidHopkins-Social-Entrepreneurship-Research-Paper.pdf. 
Irigaray, H. A. R., Cunha, G. X., \& Harten, B. A. (2016). Missão organizacional: o que a análise crítica do discurso revela? Cad. EBAPE.BR, 14(4), 920-933.

Kedmenec, I., Rebernik, M., \& Tominc, P. (2016). Social Entrepreneurship Education and Its Association with Perceived Desirability and Feasibility of Social Entrepreneurship among Business Students. Croatian Journal of Education, 18(4), 1035-1065.

Keohane, G. L. (2012). Social Entrepreneurship for the 21st Century. New York: McgrawHill Professional.

Magalhães, I. (2005). Introdução: a análise de discurso crítica. Delta: Documentação de Estudos em Linguística Teórica e Aplicada, 21(SPE), 1-9.

Oliveira, E. M. (2004). Empreendedorismo social no Brasil: atual configuração perspectiva e desafios. Revista FAE, 7(2), 9-18.

Oliveira, F. B., Sant'anna, A. S., \& Diniz, D. M. (2014). Contribuição dos cursos de graduação em administração: desenvolvimento de lideranças socialmente responsáveis? Revista Economia e Gestão, 14(34), 137-167.

Ramalho, V. C. V. S. (2005). Constituição da Análise de Discurso Crítica: um percurso teórico-metodológico. Signótica, 17(2), 275-298.

Ramos, A. G. (1989). A nova ciência das organizações: uma reconceituação da riqueza das nações. Rio de Janeiro: FGV.

Rangel, M. (2010). Fundamentos Pedagógicos: Referências significativas comuns ao ensino nas áreas de estudo gerais e profissionalizantes. Boletim Técnico do Senac: $A$ Revista da Educação Profissional, 36(3), 15-23.

Resende, V. M., \& Ramalho, V. C. V. S. (2004). Análise de Discurso Crítica, do modelo tridimensional à articulação entre práticas: implicações teórico-metodológicas. Linguagem em (Dis)curso, 5(1), 185-207.

Resende, V. M., \& Ramalho, V. (2011). Análise de discurso crítica. São Paulo: Contexto.

Rey-Marti, A., Ribeiro-Soriano, D., \& Palacios-Marqués, D. A. (2016). Bibliometric analysis of social entrepreneurship. Journal of Business Research, 69(5), 1651-1655.

Ribeiro, D. A., \& Sacramento, A. R. S. (2009). Ensino e currículo em administração: a opção brasileira. Gestão \& Planejamento, 10(2), 193-205.

Rodrigues Jr., A. (2009). Análise crítica do discurso: modismo, teoria ou método? Revista Brasileira de Linguística Aplicada, 9(1), 99-132.

Santos, L. M. L., \& Galleli, B. (2013). O Ensino de Empreendedorismo Social nos Cursos de Administração das Universidades Públicas Brasileiras. Administração Pública e Gestão Social, 5(2), 71-79.

Schumpeter, J. (1985). Teoria do Desenvolvimento Econômico: uma investigação sobre lucros, capital, crédito, juro e ciclo econômico. São Paulo: Nova Cultural. 
Shahverdi, M., Ismail, K., \& Qureshi, M. I. (2018). The effect of perceived barriers on social entrepreneurship intention in Malaysian universities: The moderating role of education. Management Science Letters, 8(5), 341-352.

Shane, S. (2002). The Foundations of Entrepreneurship. Massachusetts: Edward Elgar Publishing Limited.

Silva, A. V. (2009). Como empreendedores sociais constroem e mantêm a sustentabilidade de seus empreendimentos (Dissertação de Mestrado). Fundação Getúlio Vargas, Escola Brasileira de Administração Pública e de Empresas [EBAPE], São Paulo, SP.

Thiry-Cherques, H. R. (2009). Max Weber: o processo de racionalização e o desencantamento do trabalho nas organizações contemporâneas. Revista de Administração Pública, 43(4), 897-918.

Tragtenberg, T. (2004). Sobre educação, política e sindicalismo. São Paulo: Editora Unesp.

Weise, A. D., Quadros, J. N., Rocha, R. A., Trierweiller, A. C., Peixe, B. C. S., \& Barcellos, J. D. (2014). Análise comparativa dos cursos de graduação em administração na Alemanha, no Brasil e nos Estados Unidos da América. Revista de Administração da UFSM, 7(2), 279-295. 